\title{
Stimulation of adult neural stem cells with a novel glycolipid biosurfactant
}

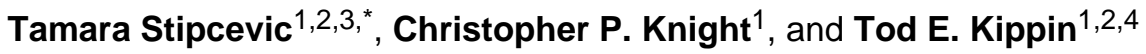 \\ ${ }^{1}$ Department of Psychological and Brain Sciences, University of California, Santa Barbara, CA \\ 93106-9660 \\ ${ }^{2}$ Neuroscience Research Institute, University of California, Santa Barbara, CA 93106-9660 \\ ${ }^{3} \mathrm{Dr}$. Stipcevic is on leave from Rudjer Boskovic Institute, Zagreb 10000, Croatia \\ ${ }^{4}$ Institute for Collaborative Biotechnology, University of California Santa Barbara, CA 93106-9660
}

\begin{abstract}
Glycolipids are amphipatic molecules which are highly expressed on cell membranes in skin and brain where they mediate several key cellular processes. Neural stem cells are defined as undifferentiated, proliferative, multipotential cells with extensive self-renewal and are responsive to brain injury. Di-rhamnolipid: a-L-rhamnopyranosyl-(1-2)a-L-rhamnopyranosyl-3hydroxydecanoyl-3-hydroxydecanoic acid, also referred to as di-rhamnolipid BAC-3, is a glycolipid isolated from bacteria Pseudomonas aeruginosa. In the previous studies di-rhamnolipid enhanced dermal tissue healing and regeneration. The present study provides the first assessment of di-rhamnolipid, and glycolipid-biosurfactants in general, on the nervous system. Treatment of neural stem cells isolated from the lateral ventricle of adult mice and cultured in defined media containing growth factors at 0.5 and $1 \mu \mathrm{g} / \mathrm{ml}$ of di-rhamnolipid increased the number of neurospheres ( 2.7 and 2.8 fold, respectively) compared to controls and this effect remained even after passaging in the absence of di-rhamnolipid. Additionally, neural stem cells treated with dirhamnolipid at 50 and $100 \mu \mathrm{g} / \mathrm{ml}$ in defined media supplemented with fetal calf serum and without growth factors exhibited increased cell viability indicating an interaction between di-rhamnolipid and serum components in the regulation of neural stem cells and neuroprogenitors.

Intracerebroventricular administration of di-rhamnolipid at 300 and $120 \mathrm{ng} /$ day increased the number of neurospheres (1.3 and 1.63 fold, respectively) that could be derived from the anterior lateral ventricles of adult mice. These results indicate that di-rhamnolipid stimulates proliferation of neural stem cells and increases their endogenous pools which may have therapeutic potential in managing neurodegenerative or neuropsychiatric disorders and promoting nervous tissue regeneration following injury.
\end{abstract}

\section{Keywords}

di-rhamnolipid; Pseudomonas aeruginosa; biosurfactant; neural stem cells; nervous tissue regeneration

\footnotetext{
*Corresponding author: Dr. Tamara Stipcevic, Department of Psychological and Brain Sciences, University of California Santa Barbara, Santa Barbara, CA 93106-2040, stipcevic@ @sych.ucsb.edu; tstipy@ gmail.com, Phone: (805)893-2791, Fax: (805)893-4303. Conflict of interest.

The authors declare no conflict of interest.
} 


\section{Introduction}

The adult human nervous system has limited ability to generate new cells which emphasizes the importance of expediting therapeutic strategies to enhance neurogenesis following injury. Given the existence of endogenous neuroprecursors throughout the adult neural axis [1], including neural stem cells (NSCs), even in non-neurogenic brain regions, an attractive alternative to stem cell transplantation strategies is to harness the potential of endogenous progenitors to repair cellular injuries by increasing and recruiting their endogenous pools. One class of compounds that has received limited attention in this regard is glycolipids.

Glycolipids are amphipatic molecules, having a hydrophilic head consisting of sugars and hydrophobic tail(s) consisting of fatty acids, with surface active properties.

Glycosphingolipids (GSLs) are glycolipids expressed on membranes of mammalian cells and involved in specific neuronal, metabolic and immune functions [2] where they participate in cell-cell and cell-substrate recognition [3], adhesion and migration [4], serve as receptors for bioactive molecules [5], modulators of signal transduction [6] regulators of cellular fate processes [7]. GSLs are particularly highly expressed in skin [7] and nervous system [8], constituting up to $12 \%$ of the total lipid content of neuronal membranes compared to up to only $2 \%$ in other tissues (AOCS lipid library). Imbalances and alterations in lipid rafts neuronal GSLs' homeostasis have been associated with the development of neurodegeneration in Alzheimer's disease [9] and neuropsychiatric disorders including major depression [10], schizophrenia [11] as well as addiction [12].

Microorganisms also produce glycolipids and the best studied ones are rhamnose containing glycolipid-biosurfactants produced by bacteria Pseudomonas aeruginosa [13]. Originally rhamnolipids attracted attention as agents for oil recovery and bioremediation [14] but there is increasing interest in the potential biomedical application of these molecules [15] due to their wide range of biological activities including formation of ion channels in lipid bilayer membranes, regulation of intracellular signaling pathways, induction of cell differentiation and cell-signaling [15]. Although rhamnolipids, and glycolipid-biosurfactants in general, have not been tested on any nervous tissue cell type nor delivered to brain, previous studies with the di-rhamnolipid BAC-3 indicate that this glycolipid has cell-type specific effects on skin [16], exhibits anti-inflammatory and immune-modulating properties [17a] [17b] and enhances healing and tissue regeneration in an animal model of full-thickness burn wounds [18a] [18b] and on chronic decubitus wound in human [19]. Given common developmental origins of skin and brain and high expression of GSLs in both, we hypothesized that BAC-3 might also be effective on nervous tissue cells and tested its activity on NSCs.

\section{Materials and Methods}

\section{Tested compound}

Di-rhamnolipid full chemical name: a-L-rhamnopyranosyl-(1-2)-a-L-rhamnopyranosyl-3hydroxydecanoyl-3-hydroxydecanoic acid, referred to as BAC-3 [16] was a gift from TajCo Inc. The purity was $>97 \%$ and checked by UV spectrum analysis with the structure confirmation by mass spectroscopy.

\section{Animals}

For all experiments 3-4 month old, male C57BL/6J (B6) mice (Jackson Laboratory, Bar Harbor, ME) were utilized. 


\section{Neurosphere assay and in vitro BAC-3 exposure}

Neurosphere-forming cells were isolated from the anterior portions of the forebrain lateral subventricular zone (SVZ) of adult C57Bl/6J mice (Jackson Laboratory) as described previously [20] [21a] [21b]. Extracted tissue was digested with enzymes $(1.33 \mathrm{mg} / \mathrm{ml}$ trypsin, $0.67 \mathrm{mg} / \mathrm{ml}$ hyaluronidase, and $0.13 \mathrm{mg} / \mathrm{ml}$ kynurenic acid; Sigma) for $35 \mathrm{~min}$ at $37^{\circ} \mathrm{C}$ in artificial cerebrospinal fluid (aCSF) followed by treatment with $0.5 \mathrm{mg} / \mathrm{ml}$ trypsin inhibitor (Sigma) in defined serum-free medium (SFM, Neurocult, Stem Cell Technologies) and mechanically dissociated into a single cell suspension. Cells were cultured under clonal conditions at 10 cells/ $\mu 1$ (5000 cells/well) in noncoated, plastic, 24-well plates (Sarsteadt) in SFM medium containing $20 \mathrm{ng} / \mathrm{ml}$ EGF (epidermal growth factor, Sigma), $10 \mathrm{ng} / \mathrm{ml} \mathrm{bFGF}$ (basic fibroblast growth factor, Sigma) and $2 \mu \mathrm{g} / \mathrm{ml}$ heparin (Sigma). The number of neurospheres (floating colonies of $\geq 100 \mu \mathrm{m}$ diameter) was counted after $7 \mathrm{~d}$. Under these conditions, it has been shown that neurosphere colonies are derived from single cells and serve as an index of the number of NSCs [20].

To examine the effect of di-rhamnolipid BAC-3 on NSC proliferation in vitro, neurospheres were dissociated into single cells and cultured as above with the addition of BAC-3 at concentrations ranging from $0.5-100 \mu \mathrm{g} / \mathrm{ml}$. For assaying cell viability under proliferative, undifferentiating, conditions cells were dissociated and plated at high density ( 700 cells $/ \mu \mathrm{l})$ in 96-well plates in SFM containing growth factors as above, allowed to grow for two days and then treated with BAC-3 for 48 hrs. Cells were incubated with Alamar blue dye (Promega) for $4 \mathrm{hrs}$ and the reduced product detected with a fluorometer (Victor plate reader, PerkinElmer). For tests performed in the presence of serum, dissociated cultures were plated at high density (1000 cells/ $\mu$ l), in 96 -well, pure coat amine plates (black, BD biosciences) in SFM containing no growth factors and supplemented with $1 \%, 5 \%$ or $10 \%$ fetal calf serum (FCS) for two days following which BAC-3 was added at 1, 50 and $100 \mu \mathrm{g} /$ ml. Viability was measured with Alamar blue dye 24 and $48 \mathrm{hrs}$ after the treatment.

\section{Intracebroventricular delivery of BAC-3}

To examine the impact of BAC-3 on NSCs in vivo, adult male C57Bl/6J (Jackson Laboratory) mice received intracerebroventriculary (ICV) BAC-3 or vehicle, 9 animals per each treatment group. Mice were anesthetized with isoflurane and BAC-3 $(1,20$, or $50 \mu \mathrm{g} /$ $\mathrm{ml}$ at a rate of $0.25 \mu \mathrm{l} / \mathrm{hr}$ producing doses of 6,120 , or $300 \mathrm{ng} /$ day) or artificial cerebrospinal fluid (aCSF) vehicle was infused unilaterally for 14 days into the lateral ventricle using a subcutaneously implanted osmotic minipump (Alzet, model 1002), attached to an intracranial canula (Alzet, brain infusion kit 3), implanted at $+1.0 \mathrm{~A} / \mathrm{P},+0.5 \mathrm{M} / \mathrm{L}$ and -2.50 $\mathrm{D} / \mathrm{V}$ relative to bregma. Following 14 days of treatment, animals underwent live decapitation and the SVZ tissue was harvested from extracted brains. Mice were handled following principles described in the National Research Council "Guide for the Care and Use of Laboratory Animals"(NIH Publication No. 80-23, revised 1996).

\section{Data Analyses}

All measurements were expressed as percent of control and then collapsed across replicates. For each measure, factorial analysis of variance ANOVAs with Fisher LSD post-hoc tests as appropriate were conducted using Statistica version 9 software; for all comparisons, $\alpha=$ 0.05 . Data were plotted as mean \pm SEM.

\section{Results}

Under proliferative conditions, in defined media supplemented with growth factors, BAC-3 dose-dependently increases NSCs/NPCs viability and neurosphere formation. To assess the effect of BAC-3 on cell viability, neurospheres were dissociated and cells were plated at 
high density with growth factors and different concentrations of BAC- 3 for a period of 48 $\mathrm{hr}$. In the range of $0.5-50 \mu \mathrm{g} / \mathrm{ml} \mathrm{BAC}-3$ increased viable cells, with increases up to $202 \%$ of control values for $1 \mu \mathrm{g} / \mathrm{ml}$ of BAC-3. The concentration of $100 \mu \mathrm{g} / \mathrm{ml}$ of BAC-3 reduced cell viability $\left(\mathrm{F}_{5,49}=9.94, \mathrm{p}<0.05\right.$; Figure $\left.1 a\right)$. To determine the effect on neurosphere formation, cells were plated at clonal density with different concentrations of BAC-3. The treatment with 0.5 and $1.0 \mu \mathrm{g} / \mathrm{ml}$ of BCA-3 increased the number of neurospheres $\left(\mathrm{F}_{4,25}=\right.$ $6.25, \mathrm{p}<0.05$; Figure $1 b$ ) with increases up to $280 \%$ of controls. Furthermore, after dissociation into single cells and replating in the absence of BAC-3, the higher productions of neurosphere-forming cells, treated with 0.5 and $1.0 \mu \mathrm{g} / \mathrm{ml}$ of BAC-3 in the previous passage, were retained $\left(\mathrm{F}_{2,51}=3.18, \mathrm{p}<0.05\right.$; Figure $\left.1 c\right)$ with increases of $32 \%$ and $46 \%$ relative to controls.

Given the known interactions between glycolipids and serum proteins, we tested BAC-3 activity on NSCs and neuroprogenitors (NPCs) in the presence of serum. Under these conditions, BAC-3 dose-dependently stimulated viability in defined media without growth factors containing 5\% and $10 \%$ FCS. At 24 and $48 \mathrm{hrs}$ following the treatment with 50 and $100 \mu \mathrm{g} / \mathrm{ml}$ BAC-3, cell viability increased up to $202 \%$ of control levels $\left(\mathrm{F}_{6,96}=2.305, \mathrm{p}<\right.$ $0.05)$. Interestingly, $100 \mu \mathrm{g} / \mathrm{ml}$ of BAC-3 in $1 \% \mathrm{FCS}$ at $48 \mathrm{hr}$ decreased cell viability similar to what was observed for the same BAC-3 concentration under proliferative conditions (defined media + growth factors; Fig $1 a$ ).

Brief measurements using Zeta particle sizer (Malvern) conducted at California NanoSystem Institute indicate that within concentration range of $125 \mu \mathrm{g} / \mathrm{ml}-1 \mathrm{mg} / \mathrm{ml} \mathrm{BAC}-3$ in phosphate buffer saline (PBS) and at $37^{\circ} \mathrm{C}$, di-rhamnolipid forms micelles of average size 5 $\eta \mathrm{m}$, whereas concentrations below $60 \mu \mathrm{g} / \mathrm{ml}$ did not result in such formations (data not shown).

In order to assess the impact of BAC-3 on NSCs in vivo, adult mice received continuous ICV administration of BAC-3 $(6,120$, or $300 \mathrm{ng} /$ day or vehicle) for 14 days after which the number of neurospheres derived from the aLV (anterior lateral ventricle) SVZ was determined. Mice treated with either 120 or $300 \mathrm{ng} /$ day showed increased (1.3 and 1.63 fold, respectively) numbers of neurosphere-forming cells compared to vehicle treated mice $\left(\mathrm{F}_{3,30}\right.$ $=4.89, \mathrm{p}<0.05)$ (Figure 3). Importantly, ICV BAC-3 treatment was well tolerated with all animals surviving treatment and exhibiting no weight loss. Gross tissue abnormalities were not observed during the isolation of the SVZ.

\section{Discussion}

This study is the first evidence that di-rhamnolipid BAC-3 stimulates proliferation of NSC and increases their endogenous pool. Specifically in vitro, neurosphere cultures grown in the presence of BAC-s contained more neurospheres-forming cells and exhibited increased proliferation under two different conditions; in serum-free medium containing growth factors (Figure 1B and C) and serum containing media without growth factors (Figure 2A and B). Importantly, the mitogenic activity of this glycolipid remained even after passaging (Figure 1C) and after withdrawal from the culture media which indicates the expansion of NSCs and further suggests that BAC-3 might be stably incorporated into the cellular membrane to alter NSCs' proliferation kinetics. Additionally, the results demonstrating that FCS modulates the effect of BAC-3 on NSCs/NPCs imply that BAC-3 interacts with serum factors and suggest a possible use of di-rhamnolipid in stimulating NSCs/NPCs following acute brain injury when brain serum concentration is elevated. Moreover, the ICV treatment with BAC-3 increased the endogenous SVZ- NSC pool. Together, the present findings demonstrate, for the first time, that glycolipid-biosurfactants can regulate NSCs. 
Although BAC-3 was able to increase cell proliferation in both absence and presence of serum, the dose response was shifted towards higher concentrations of BAC-3 and the magnitude of response increased in the latter condition which indicates that impact of BAC-3 on neuroprecursors is modulated by interaction with other factors. In aqueous solutions and around critical concentrations, glycolipids with two tails such as BAC-3 can form micelles and/or liposomes. The present findings indicate that within concentration range $125-1000 \mu \mathrm{g} / \mathrm{ml}$ in PBS and at $37^{\circ} \mathrm{C}$ BAC-3 spontaneously forms micelles of average size $5 \mathrm{~nm}$ whereas concentrations in the range that stimulated neurospheres (below $60 \mu \mathrm{g} /$ $\mathrm{ml}$ ) did not result in such formations. Thus, it is likely that the BAC-3 concentrations (0.5 and $1 \mu \mathrm{g} / \mathrm{ml}$ ), which increased NSC/NPC proliferation (Figure 1) in the presence of growth factors, but not serum, contained di-rhamnolipid in monomer form. Conversely, the cell toxicity induced by high concentration (i.e. $100 \mu \mathrm{g} / \mathrm{ml}$ ) of BAC-3 (in the absence of serum) is likely due to "detergent effects" of biosurfactants forming micelles and causing membrane lysis [16]. Although it is not possible to determine the particles sizes in the presence of serum (which itself contains particles of various sizes), it has been shown that the saccharide head of gangliosides binds strongly to serum albumin [22] [23] suggesting the formation of proteo-glyco-lipid complexes which might explain the difference in concentrationdependent effects of di-rhamnolipid obtained on cells under different conditions (serum versus no-serum).

Although it is not possible to determine the precise mechanism(s) of action of dirhamnolipid on NSCs/NPCs potential mechanisms are suggested based on existing data on BAC-3 and known interactions of glycolipids with other cellular components. Lipid rafts or "glycosynapses" [24] containing the cell adhesion molecule, $\beta 1$ integrin, and several glycosylphosphatidyl inositol-anchored molecules are involved in cell adhesion and signaling pathways and have been reported on NSCs/NPCs [25]. These microdomains on neuronal cells are nanoscale clusters rich in signaling molecules, serving as platforms for assembly and launching of signaling cascades [26]. It is known that GSLs have affinity to segregate into lipid rafts and that their presence in lipid rafts is essential for efficient intracellular signaling and also for the basal physiological functions of the receptor-type tyrosine kinases [24] [27]. Therefore, it is possible that exogenously administered glycolipids interfere with lipid raft membrane domain structures and modulate the signaling pathway triggered by bFGF and EGF and bind to both growth factor receptor systems linked to tyrosine kinase which are critical mitogens of NSCs/NPCs. In support of this hypothesis BAC-3 exhibits modest inhibitory effects on p56.sup.lck and p59.sup.fyn tyrosine kinase [17b] and acted as a protein kinase $\mathrm{C}$ activator [17b] and on neuronal cells both protein kinases $\mathrm{C}$ and $\mathrm{D}$ are activated in response to lipid raft alterations [28]. Conversely, it is also possible that glycolipid biosurfactants through their virtue of hydrophilic head bind to proteins, including receptors, on cell membranes [29] resulting in interactions with a variety of neurotransmitters systems implicated in regulation of NSCs [30]. Relevant to the observed effects on NSCs, BAC-3 inhibits dopamine receptors with a two-fold greater effect on the $\mathrm{D} 1$ subtype relative to $\mathrm{D} 2$ subtype [17b]. The latest findings indicate that bioactive brain lipids on NSCs act mainly through direct interaction with specific protein binding partner (lipid receptor, protein kinase or phosphatase, ion exchanger, or other cell signaling protein) or through formation of lipid rafts and associated signaling proteins [31].

Exogenous compounds that control of neurogenesis could improve the success rate of cellular based treatments for neurodegenerative and neuropsychiatric disorders and, despite very limited attention, glycolipid compounds have a potential to achieve such control. In vivo treatment with gangliosides has proven effective in attenuating ischemic injury in rats [32] and protecting various cell populations in several model systems of neuronal injury [33]. Additionally, intraperitoneal administration of GSL globotetraosylceramide has been shown to exhibit marked anti-depressive activity on the forced swimming test in mouse [34]. 
Importantlly, GSLs appear to be safe for long-term administration (up to 5 years; [35] and are therapeutically active in nanomolar range which was demonstrated for novel drug for multiple sclerosis intended for oral use-fingolimod- from Novartis [36]. The present results demonstrate that BAC-3 stimulates endogenous NSCs thus, it is anticipated that clarification of the sites and mechanisms underlying the induction and modulation of neurogenesis by BAC-3 will indicate novel strategies for the treatment of various brain diseases. Further promise for the clinical usage of glycolipid compounds lies in their property to potentially produce stable changes in the cellular membrane architecture which could allow the development of drugs that would require limited (perhaps one time) administration instead of continual use to treat chronic illness.

\section{Acknowledgments}

This work was supported by National Institute on Drug Abuse grant DA027115. Paradigm Biomedical Inc. NY, USA is the owner of patents on rhamnolipids.

\section{References}

1. Weiss S, Dunne C, Hewson J, Wohl C, Wheatley M, Paterson AC, Reynolds BA. Multipotent CNS stem cells are present in the adult mammalian spinal cord and ventricular neuroaxis. J Neurosci. 1996; 16:7599-609. [PubMed: 8922416]

2. Ikami T, Ishida H, Kiso M. Synthesis and biological activity of glycolipids, with a focus on gangliosides and sulfatide analogs. Methods Enzymol. 2000; 311:547-68. [PubMed: 10563349]

3. Miyakoshi LM, Todeschini AR, Mendez-Otero R, Hedin-Pereira C. Role of the 9-O-acetyl GD3 in subventricular zone neuroblast migration. Mol Cell Neurosci. 2012; 49:240-9. [PubMed: 21930212]

4. Yanagisawa M, Taga T, Nakamura K, Ariga T, Yu RK. Characterization of glycoconjugate antigens in mouse embryonic neural precursor cells. J Neurochem. 2005; 95:1311-20. [PubMed: 16219035]

5. Fantini J, Barrantes FJ. Sphingolipid/cholesterol regulation of neurotransmitter receptor conformation and function. Biochim Biophys Acta. 2009; 1788:2345-61. [PubMed: 19733149]

6. Yu RK, Yanagisawa M. Glycosignaling in neural stem cells: involvement of glycoconjugates in signal transduction modulating the neural stem cell fate. J Neurochem. 2007; 103:39-46. [PubMed: 17986138]

7. Wennekes T, van den Berg RJBHN, Boot RG, van der Marel GA, Overkleeft HS, Aerts JMFG. Glycosphingolipids-Nature, Function, and Pharmacological Modulation. Angew Chem Int Ed. 2009; 48:8848-8869.

8. Yu RK, Nakatani Y, Yanagisawa M. The role of glycosphingolipid metabolism in the developing brain. J Lipid Res. 2009; 50:440-445.

9. Ariga T, McDonald MP, Yu RK. Sphingolipids: Role of ganglioside metabolism in the pathogenesis of Alzheimer's. J Lipid Res. 2008; 49:1157-1175. [PubMed: 18334715]

10. Kornhuber J, Reichel M, Tripal P, Groemer TW, Henkel AW, Mühle C, Gulbins E. The role of ceramide in major depressive disorder. Eur Arch Psychiatry Clin Neurosci. 2009; 259:199-204.

11. Narayan S, Head SR, Gilmartin TJ, Dean B, Thomas EA. Evidence for disruption of sphingolipid metabolism in schizophrenia. J Neurosci Res. 2009; 87:278-88. [PubMed: 18683247]

12. Valdomero A, Hansen C, de Burgos NG, Cuadra GR, Orsingher OA. GM1 ganglioside enhances the rewarding properties of cocaine in rats. Eur J Pharmacol. 2010; 630:79-83. [PubMed: 20044989]

13. Jarvis FG, Johnson MJ. A glyco-lipid produced by Pseudomonas aeruginosa. J Am Chem Soc. 1949; 71:4124-4126.

14. Maier RM, Soberon-Chavez G. Pseudomonas aeruginosa rhamnolipids: biosynthesis and potential applications. Appl Microbiol Biotechnol. 2000; 54:625-633. [PubMed: 11131386]

15. Rodrigues L, Banat IM, Teixeira J, Oliveira R. Biosurfactants: potential applications in medicine. J Antimicrob Chemother. 2006; 57:609-618. [PubMed: 16469849] 
16. Stipcevic T, Piljac T, Isseroff RR. Di-rhamnolipid from Pseudomonas aeruginosa displays differential effects on human keratinocyte and fibroblast cultures. J Dermatol Sci. 2005; 40:141-3. [PubMed: 16199139]

17. Piljac G, Piljac V. Pharmaceutical preparation based on rhamnolipid. United States Patent No. 1995a; 5:466, 675.

17. Piljac G, Piljac V. Immunological activity of rhamnolipids. United States Patent No. 1995b; 5:466, 675.

18. Stipcevic T, Piljac A, Piljac G. Enhanced healing of full-thickness burn wounds using dirhamnolipid. Burns. 2006a; 32:24-34. [PubMed: 16380213]

18. Stipcevic, T.; Piljac, T.; Piljac, J.; Dujmic, T.; Piljac, G. Use of rhamnolipids in wound healing, treatment and prevention of gum disease and periodontal regeneration. United States Patent No. 7,129,218. 2006b.

19. Piljac A, Stipcevi T, Piljac-Zegarac J, Piljac G. Successful treatment of chronic decubitus ulcer with $0.1 \%$ dirhamnolipid ointment. J Cutan Med Surg. 2008; 12:142-146. [PubMed: 18544299]

20. Hitoshi, S.; Kippin, T.; van der Kooy, D. Culturing adult neural stem cells: Application to the study of neurodegenerative and neuropsychiatric pathology. In: Seki, T.; Sawamoto, K.; Parent, JM.; Alvarez-Buylla, A., editors. Neurogenesis in the Adult Brain II. Tokyo (JP): Springer; 2011. p. 189-207.

21. Kippin TE, Kapur S, van der Kooy D. Dopamine specifically inhibits forebrain neural stem cell proliferation, suggesting a novel effect of antipsychotic drugs. J Neurosci. 2005a; 25:5815-5823. [PubMed: 15958748]

21. Kippin TE, Martens DJ, van der Kooy D. p21 loss compromises the relative quiescence of forebrain stem cell proliferation leading to exhaustion of their proliferation capacity. Genes Dev. 2005b; 19:756-767. [PubMed: 15769947]

22. Venerando B, Roberti S, Sonnino S, Fiorilli A, Tettamanti G. Interactions of ganglioside GM1 with human and fetal calf sera formation of ganglioside-serum albumin complexes. Biochim Biophys Acta. 1982; 692:18-26. [PubMed: 6184073]

23. Schengrund CL, Mummert CM. Exogenous gangliosides. How do they cross the blood-brain and how do they inhibit cell proliferation. Ann NY Acad Sci. 1998; 845:278-84. [PubMed: 9668362]

24. Hakomori SI. The glycosynapse. Proc Natl Acad Sci USA. 2002; 99:225-232. [PubMed: 11773621]

25. Yanagisawa M, Yu RK. The expression of glycoconjugates in neural stem cells. J Lipid Res. 2009; 50:440-445.

26. Iwabuchi K, Nakayama H, Iwahara C, Takamori K. Significance of glycosphingolipid fatty acid chain length on membrane microdomain-mediated signal transduction. Lett. 2010; 584:16421652.

27. Mutoh T, Yano S, Yamamoto H. Signal transduction mechanisms for the survival and death of neurons and muscle cells: modulation by membrane lipid rafts and their abnormality in the disorders of the nervous system. Nihon Shinkei Seishin Yakurigaku Zasshi. 2004; 24:199-203. [PubMed: 15484820]

28. Cabrera-Poch N, Sánchez-Ruiloba L, Rodriguez-Martinez M, Iglesias T. Lipid raft disruption triggers protein kinase $\mathrm{C}$ and Src-dependent protein kinase $\mathrm{D}$ activation and Kidins220 phosphorylation in neuronal cells. J Biol Chem. 2004; 279:28592-602. [PubMed: 15096499]

29. Evans SV, MacKenzie CR. Characterization of protein-glycolipid recognition at the membrane bilayer. J Mol Recognit. 1999; 12:155-168. [PubMed: 10398406]

30. Young SZ, Taylor MM, Bordey A. Neurotransmitters couple brain activity to subventricular zone neurogenesis. Eur J Neurosci. 2011; 33:1123-32. [PubMed: 21395856]

31. Bieberich E. It's a lipid's world: Bioactive lipid metabolism and signalling in neural stem cell differentiation. Neurochem Res. 2012; 37:1208-1229. [PubMed: 22246226]

32. Seren S, Rubini R, Lazzaro A, Zanoni R, Fiori MG, Leon A. Protective effects of a monosialoganglioside derivative following transitory forebrain ischemia in rats. Stroke. 1990; 21:1607-1612. [PubMed: 2237955] 
33. Figliomeni B, Bacci B, Panozzo C, Fogarolo F, Triban C, Fiori MG. Experimental diabetic neuropathy: effect of ganglioside treatment on axonal transport of cytoskeletal proteins. Diabetes. 1992; 41:866-871. [PubMed: 1377137]

34. Masuda Y, Sugiyama T. The effect of globopentasylceramide on a depression model, mouse forced swimming. Tohoku J Exp Med. 2000; 191:47-54. [PubMed: 10896039]

35. Schneider JS, Sendek S, Daskalakis C, Cambi F. GM1 ganglioside in Parkinson's disease: Results of a five year open study. J Neurol Sci. 2010; 292:45-51. [PubMed: 20206941]

36. Stessin AM, Gursel DB, Schwartz A, Parashar B, Kulidzhanov FG, Sabbas AM, Boockvar J, Nori D, Wernicke AG. FTY720, sphingosine 1-phosphate receptor modulator, selectively radioprotects hippocampal neural stem cells. Neurosci Lett. 2012; 516:253-8. [PubMed: 22507238] 


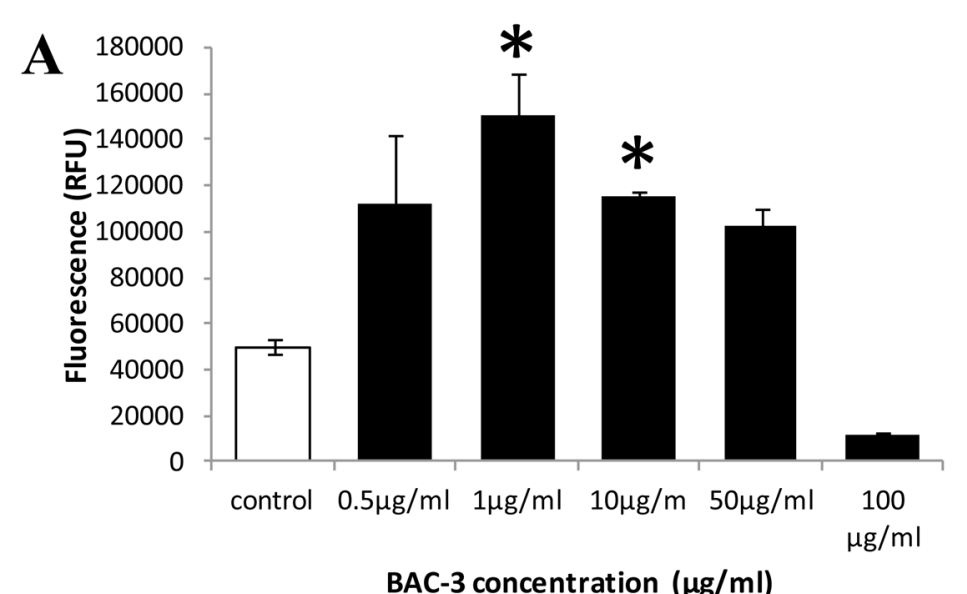

BAC-3 concentration $(\mu \mathrm{g} / \mathrm{ml})$
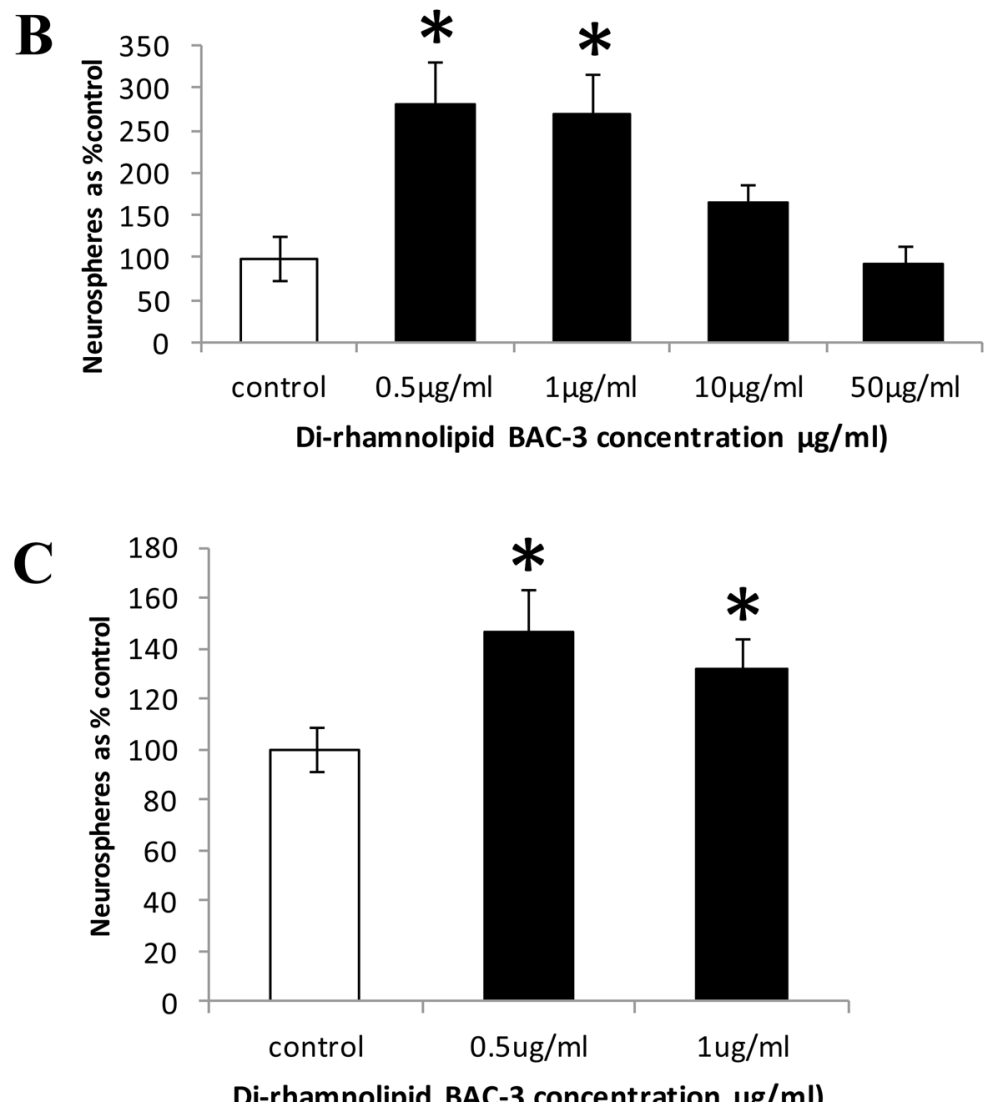

Figure 1. A, B and C. Di-rhamnolipid BAC-3 dose dependently increases neurosphere formation and neuroprecursor viability in vitro

(A). Viability of dissociated neurosphere cultures (700 cells $/ \mu \mathrm{l}$ in SFM+EGF+bFGF) $48 \mathrm{hrs}$ after treatment with BAC-3 at $0.05,1$, or $10 \mu \mathrm{g} / \mathrm{ml}$ measured with Alamar blue dye (Promega) (B). Neurosphere cultures (10 cells $/ \mu \mathrm{l}$ in SFM+EGF+bFGF) treated with BAC-3 at 0.5 and $1 \mu \mathrm{l} / \mathrm{ml}$. (C). Neurosphere-cultures (10 cells $/ \mu 1$ in SFM+EGF+bFGF) treated with 0.5 and $1 \mu \mathrm{g} / \mathrm{ml}$ of BAC -3 at the time of plating and then passaged 7 days later in the absence of BAC-3. $* \mathrm{p}<0.05$ versus vehicle. 

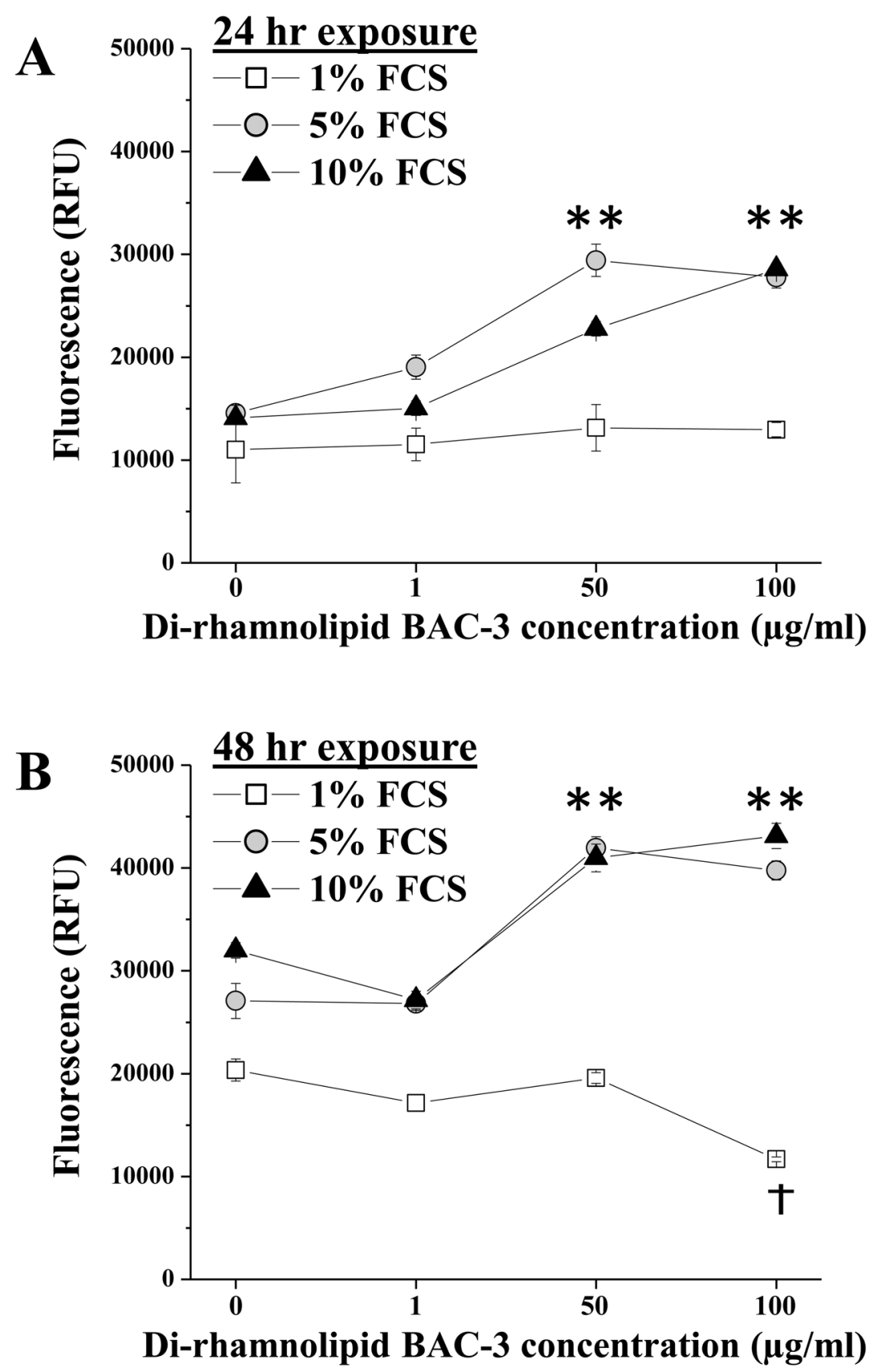

Figure 2. A and B. Di-rhamnolipid BAC-3 increases NSCs/NPCs viability in high serum conditions

Neurosphere cultures (1000 cells/ $\mu$ in SFM without growth factors) were treated with $1 \%$, $5 \%$, or $10 \%$ FCS and $1-100 \mu \mathrm{g} / \mathrm{ml}$ BAC-3 and viability was assessed with Alamar blue dye (Promega) at 24 and $48 \mathrm{hrs}$ later. $* * \mathrm{p}<0.05$ versus vehicle for both $5 \%$ and $10 \%$ FCS. 


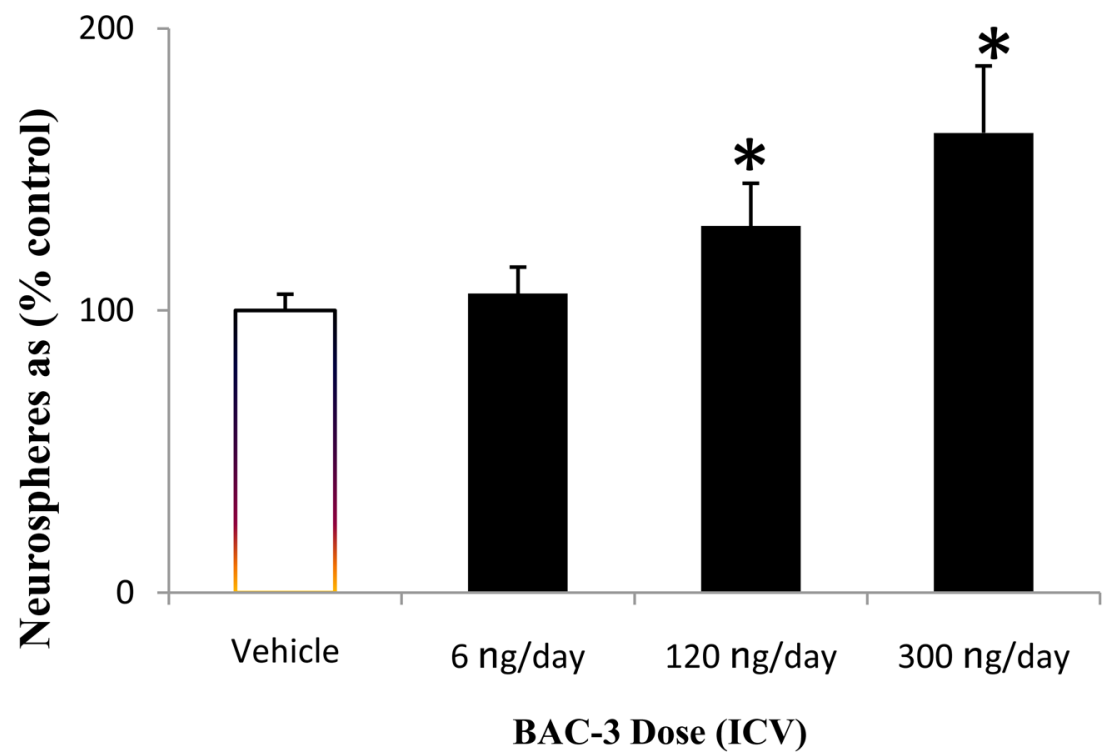

Figure 3. Instraventricular treatment with di-rhamnolipid BAC-3 increases NPCs/NPCs endogenous pools

BAC-3 at 6, 120, or $300 \mathrm{ng} /$ day or aCSF vehicle was infused unilaterally for 14 days into the lateral ventricle using a subcutaneously implanted osmotic minipump. After 14 days of treatment primary neurosphere cultures were established from all dissected SVZs and 7 days later total neurospheres were counted and expressed as percent control. ${ }^{*} \mathrm{p}<0.05$ versus vehicle. 